This item was submitted to Loughborough's Research Repository by the author.

Items in Figshare are protected by copyright, with all rights reserved, unless otherwise indicated.

\title{
The diverse patterns of work-related business travel: accounting for spatial scale
}

PLEASE CITE THE PUBLISHED VERSION

http://dx.doi.org/10.1080/23800127.2016.1245091

\section{PUBLISHER}

(C) Taylor \& Francis

\section{VERSION}

AM (Accepted Manuscript)

\section{PUBLISHER STATEMENT}

This work is made available according to the conditions of the Creative Commons Attribution-NonCommercialNoDerivatives 4.0 International (CC BY-NC-ND 4.0) licence. Full details of this licence are available at: https://creativecommons.org/licenses/by-nc-nd/4.0/

\section{LICENCE}

CC BY-NC-ND 4.0

\section{REPOSITORY RECORD}

Hislop, Donald. 2019. "The Diverse Patterns of Work-related Business Travel: Accounting for Spatial Scale". figshare. https://hdl.handle.net/2134/23476. 
The Diverse Patterns of Work-related Business Travel: Accounting for Spatial Scale

Dr Donald Hislop

Accepted for publication in: Applied Mobilities

( $\square$ http://dx.doi.org/10.1080/23800127.2016.124509)

\author{
School of Business and Economics \\ Loughborough University, \\ Loughborough, \\ UK, LE11 3TU
}

Email: $\underline{\text { d.hislop@lboro.ac.uk }}$

Phone: 00441509228826

Fax: 00441509223960

\title{
Author biography
}

Donald is a Reader in the Sociology of Contemporary Work Practices in the School of Business and Economics at Loughborough University. In relation to the topic of mobile working, Donald's research focuses on two specific, overlapping themes: the extent to which business people work while travelling on work-related journeys, and the way in which mobile computer and communication technologies are used in these work activities. He has published extensively on this topic in a diverse range of journals including Work, Employment and Society, New Technology, Work and Employment, Information and Organization and Mobilities. 
The Diverse Patterns of Work-related Business Travel: Accounting for Spatial Scale

\section{$\underline{\text { Abstract }}$}

In understanding workers' work-related mobility patterns it is more accurate to talk of mobilities, rather than mobility, as a heterogeneous range of different types and patterns of work-related travel are undertaken (Jones 2010). It is suggested here that the spatial mobility of workers can involve undertaking quite different types of journeys on different spatial scales, and that the diverse spatial scales over which business travel occurs need to be taken greater account of. In the present paper, this is done via utilizing and illustrating Hislop's (2016) framework on the spatial scales of business travel. This framework distinguishes between four broad scales and journey types: localized landbased travel, long distance land-based travel, short haul plane-based journeys and long haul planebased journeys. To illustrate the type of journeys undertaken at each spatial scale, empirical data is drawn from a study of UK business travellers involving journeys undertaken by car, plane, and train A number of illustrative vignettes are presented which give rich insights into the various types of workers who regularly travel for work, the type of journeys they undertake, and some of the key impacts that their work and travel patterns have on their non-work lives.

\section{$\underline{\text { Keywords }}$}

Business travel, spatial scale, travel time 


\section{Introduction}

Research suggests that an increased proportion of workers are regularly required to engage in workrelated travel in order to carry out their jobs (Beaverstock et al 2010, Felstead et al 2005, Jeong et al 2013). This is symptomatic of Castells' suggestion that the 'flow' of people, goods, information etc. is a key feature of the contemporary global economy (Knox et al 2008), with flows defined as 'repetitive, programmable, sequences of exchange and interaction between physically disjointed positions held by social actors ...' (Castells 1996, p. 412). While our understanding of the character and dynamics of work-related travel has increased with the growing amount of academic interest devoted to the topic, significant gaps in knowledge still remain. The aim of this paper is to address one such gap: how the diverse spatial scales that business journeys occur over affect the character of people's work, and potentially their non-work lives. This aim is achieved through utilizing and illustrating a conceptual framework which is sensitive to such issues (Hislop 2016). This aim fits with one of the key aims of Applied Mobilities, to publish theoretically informed, applied research which has a practice-oriented perspective

Such a task is made important due to the neglect of this aspect of work-related mobility in the main typologies of business travel that have been developed (for example Lilischkis 2003, Wickham \& Vecchi 2010). This is an important topic to consider not just because of its neglect, but also because there is a risk that inadequately accounting for different spatial scales is likely to result in a partial view of work-related mobility patterns occurring. Further, being sensitive to the spatial scales that business travel involves helps take account of the ways in which the time involved in undertaking work-related journeys affects people's travel and work time. For example, the significant temporal demands of undertaking long haul, plane-based journeys means that, for those business people 
regularly undertaking such journeys, the demands of work-related travel are significant and extensively shape the nature of people's working lives. Such journeys can be contrasted with more localised, car-based travel, involving multiple short journeys within a confined geographical area, where the impact of work-related travel on the character of people's working lives is likely to be substantially different.

The paper meets its aim via the analysis of survey and interview data collected during a study of UK business travellers. This analysis utilizes and builds on a framework developed by Hislop (2016) which differentiates between four distinct spatial scales for business travel. Qualitative empirical data is presented which provides insights into the distinct type of journeys undertaken at each spatial scale, how the type of work undertaken at different spatial scales can vary, how the experience of business travel on each scale is distinct, and also how travel at each scale has implications for working time, and the character of people's work patterns.

The paper begins by evaluating the existing literature on how the heterogeneity of work-related mobility patterns are conceptualized. This section concludes by suggesting that Hislop's (2016) framework on the different spatial scales of work-related journeys has the potential to address the neglect that currently exists around how the spatial scale of work-related journeys can crucially shape the nature of people's work and non-work lives. Following this, the paper outlines how the research data that is presented on the travel experiences of UK business travellers was collected. The focus then shifts to the presentation of the paper's empirical findings, which are focussed on illustrating Hislop's (2016) framework on the distinct spatial scales of work-related journeys. This is done via utilizing both the survey and interview data. Survey data is utilized to provide an overview into the character of the travel patterns and type of travellers who undertake journeys at each 
spatial scale. Secondly, interview data is utilized to provide illustrative vignettes into how the various spatial scales that work-related travel spans impacts on people's work and travel experiences. The paper then concludes with a discussion which reflects on the key themes explored in the paper.

\section{The Contemporary Importance and Diversity of Work-related Mobility Patterns}

In the last few decades there has been a noticeable increase in the proportion of workers whose work regularly requires them to travel (Beaverstock et al 2010, Felstead et al 2005). For example, in relation to international travel to and from the UK, survey data showed that the number of travellers entering and leaving the UK for business purposes trebled in the 10 years between 1997 and 2006 (Beaverstock \& Faulconbridge 2010).

A key underlying cause of this increase in the amount of work-related travel being undertaken is the increasingly globalised nature of economic activity, which involves collaboration between geographically dispersed people and organizations. Despite advances in information and communication technologies, which facilities remote communication and collaboration, the success of such geographically dispersed activity requires the regular physical movement of people between locations, in order to undertake work activities in particular locations. In Castells' terms, in a 'network society', the physical 'flow' of workers is an activity that is increasingly necessary to sustain geographically dispersed economic activity (Beaverstock et al 2010).

In making sense of work-related mobility patterns, arguably one of the most important factors to take account of is the heterogeneity of travel patterns engaged in by different types of workers. Key 
variables underpinning this diversity include the regularity with which people travel, the range of locations people travel to, the mode/s of transport utilized, the purpose of the journeys undertaken, the duration of business trips, journey time and the distances travelled (which are not necessarily directly related), to name but a few. To take account of this diversity, a number of writers have developed typologies of business travel/travellers/journeys.

Lilischkis (2003) develops a typology which differentiates between five distinctive types of mobility. This includes 'on-site movers' (workers who are regularly mobile within the confines of a particular location or site) and 'carriers' (workers responsible for the transportation of people or goods such as train drivers, couriers etc.). Lilischkis also differentiates between three other types of business traveller using the labels 'yoyos', 'pendulums' and 'nomads', with 'yoyos' being workers who regularly travel to different locations for their work, but who have a fixed, static base which is their primary work location, 'pendulums' being people who have to regularly travel for work, but who have two separate static locations that they can work from and oscillate between, and 'nomads', workers who regularly travel for work, but who have no static base and who continually working from different locations.

The second typology considered here has some overlaps with the typology developed by Lilischkis and was developed by Wickham \& Vecchi (2010) based on a study of the Dublin software industry. It distinguishes between three types of mobility pattern (commuter, explorer and nomad) based on two dimensions, the number of places that someone regularly has to visit, and the number of new/novel places that someone regularly has to visit. The main limitation of both these typologies is the neglect of the spatial scale and distances involved in people's mobility patterns. For example, the travel patterns of all the different mobile work types would be very different if they involved travel at a local, regional, national, or inter-continental scale. To address this Hislop (2016) developed a 
framework on mobile work which differentiated between work-related journeys which occurred on four distinct spatial scales.

\section{Diverse Journey Types and Spatial Scales in the Work-related Mobility of Managerial and}

\section{Professional Workers}

In discussing the spatial scales involved in business travel it is useful to begin by acknowledging that not all work-related travel involves long distance journeys, or international travel and may involve more 'mundane' and localized car-based journeys between locations within a circumscribed geographic area. The framework developed by Hislop (2016) focusses narrowly on spatial scale in terms of geographic distance. This is done deliberately, in order to highlight the importance of this (somewhat) neglected dimension of business travel, which impacts significantly on both the nature of business travel, as well as the type of workers undertaking it. This framework distinguishes between four separate scales/journey types which involves combining the broad distances travelled on a journey and the primary mode of transport used (see Figure 1). However, it is useful to acknowledge that within each broad journey type, journeys with a diverse range of characteristics are possible. The first two travel scales involve land-based travel (i.e. any mode of transport other than plane). In understanding such journeys a distinction is made between two journey types, localized land-based travel, and long distance land-based travel. Further, in considering plane-based journeys which involve travelling on a greater spatial scale, over longer distances, a distinction is made between two types of journey: short-haul plane-based travel and long-haul plane-based travel. 
Localized land-based travel represents the most geographically constrained spatial scale, where business journeys occur within a relatively small geographic area such as a particular town or suburb of a city. These types of journey are most likely to be undertaken by car, and at this spatial scale travel is over relatively short distances and individual journeys may not be time consuming. Often, workers undertaking such journeys may complete a number of separate, short journeys to different locations within a single day. Further, engaging in such work-related travel patterns typically does not involve overnight stays away from home, as workers are generally never too remote from home, and are able to return there at the end of the working day. Examples of workers engaging in such work-related travel patterns are diverse and include health \& social care professionals (Ferguson 2009, Wibberley 2013), mobile hairdressers (Cohen 2010), police and other emergency service workers (Sørensen \& Pica 2005, Pica \& Sørensen 2008), and mobile service/support engineers (Axtell \& Hislop 2008).

Long-distance land-based travel involves work-related journeys being undertaken typically by car or train and involving travel over significantly greater distances than with localized journeys. Journeys at this spatial scale can often be long and time-consuming. For workers who regularly undertake such journeys, the process of travel itself can start to become relatively time consuming, and may extend the working day significantly (for example, undertaking such journeys to arrive at a 9am meeting may involve starting journeys very early in the morning). Engaging in such travel patterns may also regularly require workers to stay away from home overnight. The type of workers who engage in this type of travel include professionals with a geographically dispersed client-base, or managers who have responsibilities for business within a number of locations (such as within a particular region, state or country). Ultimately, regularly undertaking such journeys can impinge significantly on people's non-work lives due to a combination of the time involved in travelling, the 
need to often incorporate overnight stays within such trips, and the fact that in order to fit the needs of clients that such journeys are often undertaken during traditional non-work time such as evenings or weekends. Examples of workers engaging in such travel patterns are management consultants (Hislop \& Axtell 2009), sales staff (Laurier \& Philo 2003), or managerial and professional workers (Felstead et al 2005).

Short-haul plane-based travel is the third spatial scale in Hislop's (2016) framework, which involves relatively short plane-based journeys. Such journeys may be between locations within a single county, or be intra-continental (such as flying between countries within Europe). While flight times on such journeys may be relatively short, the process of navigating airport bureaucracies, combined with the multi-modal nature of such journeys, where travel time is also involved in getting to or from airports, means such journeys can often be time consuming. Further, the practicalities of undertaking such journeys generally means that travellers undertaking them often require to stay away from home for at least one night. Thus, regularly undertaking such journeys can significantly impact on people's non-work time, due to both requirements to travel outside work hours, or to stay away from home. A reasonable amount of academic attention has been devoted to examining such work-related travel (see for example Gustafson 2006, Hislop \& Axtell 2015, Holm \& Kendall 2008, Jeong et al 2013, Lassen 2009).

Long-Haul Plane-based Travel is the fourth spatial scale in Hislop's (2016) framework. At this spatial scale, the journeys undertaken are both very time consuming, and physically demanding, due to the length of journeys and also that they often involve travelling across multiple time zones. Such journeys are typically inter-continental, but within large nation states such as China or the USA, can be intra-continental. The physical and temporal demands of this type of journey are such that 
people often utilize electronic communication as a means to minimize the need to undertake such journeys (Faulconbridge et al 2009). Such work-related travel is undertaken by workers in global professional service firms (Faulconbridge \& Muzio 2008), and senior level managerial and professional staff in global multinationals (Jones 2010). Travel at this scale has quite significant implications for people's non-work lives, as it can involve being absent from home for extended periods, and produce fatigue in people due to the physical demands of the journeys.

Hislop's (2016) spatial scales framework has the potential to provide insights into the relatively neglected topic of how the diverse spatial scales of business travel affects the nature of people's work and travel time, and the impacts of business travel for their non-work lives. Before examining the research data on workers experiences of travel at each of the four scales, the research methods utilized to collect the data are outlined.

\section{Methodology}

The data that is presented here is taken from a study of UK business travellers. Data was collected via a two stage approach, where surveys were distributed during the initial stage of data collection, and semi-structured interviews were conducted with a sample of survey respondents during the second stage. In order to identify relevant travellers during the first stage of data collection, surveys were distributed while business travellers were in the process of undertaking work-related journeys. To take account of the diversity of means of transport that business travellers commonly make use of surveys were distributed to business people travelling by train, car and plane. To identify appropriate research subjects data collection was undertaken by distributing surveys to business people travelling on trains, while passing through an airport and a motorway service station. All 
surveys were distributed in the English Midlands, and were distributed at each location during a range of times over the course of two to three days. The survey methodology utilized was successful with over 1100 surveys being distributed, and almost 700 being returned, giving a response rate of over $60 \%$. The second stage of data collection was undertaken to obtain more detailed qualitative data. This was done by conducting follow up interviews with a selection of survey respondents. A total of 48 survey respondents were interviewed (19 train passengers, 15 airport travellers and 14 car travellers). Interviews lasted an average of 30 minutes. The interviews that were conducted were semi-structured, and asked people about a range of topics including: the extent to which they worked while travelling, the type of work activities they undertook, the technologies (if any) they used in carrying them out, and the extent to which business travel affected people's experiences of work-life balance. The interview sample was representative of the survey population in terms of gender, occupation and work patterns while travelling. Due to the empirical focus of this paper, the interviews are the main data source utilized here.

\section{Findings}

The focus here is to provide illustrative vignettes of particular travellers who were interviewed, whose work-related travel patterns were predominantly at each of the four spatial scales in the framework examined. As outlined earlier, at each spatial scale the type of journeys undertaken and the type of workers undertaking business travel is diverse. Thus, illustrating each spatial scale via the use of a single vignette, gives a partial view of work and travel at each scale, and cannot illustrate the diversity involved. However, the benefit of using such vignettes is that it provides detailed qualitative insights into the differences in work and travel that can exist at each spatial scale. The vignettes that have been used here have also been selected to illustrate key features of work and 
travel at each scale, in terms of factors such as the type of work carried out, as well as the dominant modes of transport utilised.

\subsection{Localised Land-based Journeys: Mobile Service Engineers}

This vignette focusses on the work of a (male) 'mobile service engineer' who serviced and repaired materials handling equipment (such as fork lift trucks) at client sites within a small defined geographic region. The job can be described as a skilled manual occupation. Working hours were standard ('we do a 9 hour day $7.30 \mathrm{am}$ till $5 \mathrm{pm}$ ' - there is a 30 minute unpaid lunch break, 'when I'm on my lunch that's unpaid, and that's my time, so nothing gets done then'). The engineers were paid for the hours they worked, thus if they worked outside of these hours, as they occasionally needed to do, they were paid overtime. Further, work was organized such that the engineers never started their working day before 7am. While the engineers had autonomy when undertaking their service and repair work, they had less autonomy in deciding what jobs they do, and in which order they should visit clients, with such decisions being made by a centralised office ('the jobs are actually allocated and put into the system by a dispatcher in the office'). While the engineers had workrelated mobile phones, they typically did not communicate directly with clients by phone, with this being done by the office. Thus the only direct communication engineers had with clients was when they were on site, with work-related mobile phone calls largely involving communication with other company employees such as management and office dispatchers.

For the engineer interviewed, work-related travel was undertaken in a company van, with the working day beginning (always 7am) and finishing (approximately 5.30pm every day) at the engineer's home, as there was no formal office base. Within the course of any single working day a range of client sites were visited. The driving was urban, within the boundary of a large city ('a lot of 
town centre driving'). Every individual work-related journey typically took less than one hour with, the size of the work region being described as taking 'one and a half hours, worst case', to drive across. The main factor that could extend journey time, and sometimes be a source of frustration, was traffic congestion and accidents, with journey times being described as 'the great unknown'.

Due to both the highly regulated and typically fixed working hours, and lack of need to communicate directly with clients when off site, the non-work impact of the engineer's job, and work-related travel, in terms of stress, fatigue, or as a cause of intrusion into non-work time, was relatively nonexistent. The main way in which work impacted on his non-work life was when he had to work late, beyond standard $5 \mathrm{pm}$ in order to finish a particular job, which occasionally involved working 1-2 hours of overtime. Further, the nature of the engineer's job meant that when he got home he was never interrupted by work-related issues ('when I get back home, that's it, the phone's in the cupboard until $7 o^{\prime}$ clock the next morning'). Fundamentally, while traffic congestion could be a cause of frustration during working hours, the engineer's job, and the work related travel had a negligible self-reported negative impact on the engineer's non-work life.

\subsection{Long-distance land-based Travel: National Sales Manager}

This vignette examines the situation of a female sales-person, who worked for a large UK organization that provides a range of support services to organizations, and is responsible for the sale of corporate cleaning services. She had a physical base in one of the organization's locations in a large Yorkshire city. Her mobility involved visiting clients in order to tender for cleaning contracts. In talking about her work she said, 'my job involves going out to see a prospective client and doing a survey for their cleaning requirements, or talking to them ... I have to do research to find out what their needs are .. and survey the actual building.' Thus, the need for physical mobility was partly to 
establish inter-personal relations with potential clients, but also due do to a need to physically see the buildings in which cleaning services were being tendered for.

Her typical weekly work pattern involved spending two or three days per week in the office, and two to three days per week travelling to different client sites. Her responsibilities were UK-wide, and thus she regularly travelled all over the country, and most journeys undertaken were inter-city and typically more than two hours in duration. In describing the work patterns at the time of the interview, she said, 'this week, Monday Tuesday I was in London, Wednesday Thursday, Friday in the office in XX. Friday of last week I was in Glasgow .. then I could travel to Preston, I could be in the Midlands .. before that I was in the very West of Wales, Aberystwyth'. Travel was typically by train or car, with the choice of mode of transport being used, 'determined by where exactly I am going.' Her journeys were typically done within the course of a single day, and rarely required her to stay away overnight. However, the distances travelled, combined with the need to be at client sites for early meetings meant that when she travelled for work she typically had long working days, having to leave home early, and arrive home late, and talked about getting up at times such as 05.30am, and not departing for home from client sites until the end of normal office hours, between 5-6pm.

Another key feature of this travellers work was its communication intensity. Due partly to the extent of this interviewee's mobility, she utilized a work-related smartphone to provide mobile access to email. The interview with this traveller revealed that she not only had to deal with a large quantity of emails ('you get this horrendous volume...'), but she also felt compelled to be constantly monitoring email, whatever she was doing, and wherever she was ('I never switch my phone off, even when I am on annual leave'), and felt under pressure to respond promptly to client-related communications (it's my clients that impose deadlines'). Finally, the non-work impact of this travellers work resulted 
both from this felt compulsion to respond promptly to work-related communications, irrespective of time, as well as the need to regularly leave home early and arrive home late due to the need to undertake the work-related journeys that were essential to her work. The impact of work-related travel demands on her non-work life were felt to have become more significant since having a child ('I have a little boy who is 22 months old and everything has changed since having him .. the freedom [related to travel] hasn't felt the same ..')

\subsection{Short-haul plane-based travel: construction project manager}

The traveller examined at this spatial scale was a male 'project manager' who worked for a property management company that specialised in large retail developments. While his formal corporate address was London, he lived in a city in the South West of England. At the time of the research, he was working on a retail development in a Scottish city. His responsibilities were primarily to manage the on-site building work. This involved working on-site extensively, 'the bulk of my time is spent onsite with contractor and the design teams to ensure that its delivered to what we're expecting it to $b e^{\prime}$. While he had an office-base for when he wasn't on-site, he also regularly worked at home. He described his typical work and travel pattern at the time of the research as follows: 'Monday morning, fly to XX. I will come home Wednesday night. Thursday I'll go to the office in London and Friday I will either work from home, or I'll be jumping in the car and driving somewhere for a meeting'.

The key aspects to this project manager's work were that, as described above, he was highly mobile, continually travelling for work, that he was highly autonomous in how he organized his work, and that his work was demanding and communication intensive. In terms of autonomy, he did not have fixed working hours, and required to manage his time effectively to ensure work is completed on 
time. While he required to be on-site much of the time, he had a significant amount of autonomy over when and how he worked. He managed this by working long hours when away from home ('when I am away from home I do work 12-14 hour days and not bat an eyelid because my family's not going to be compromised'), and being more sensitive to family demands when working at home ('I'm not going to be actively trying to get things done once [family] start coming home and milling round the house').

The extensive amount of travel undertaken was largely shaped by the need to be at the construction site to manage architects, contractors etc., to ensure work was carried out to schedule and deal with any issues that emerged. Such work required him to be on site not just for face-to-face interactions, but also to be able to physically see problems, and make judgements on how to solve them. In terms of mobility, construction sites are arguably a key mobility nexus, where people, artefacts, information etc. have to be physically brought together in a single location, in a carefully managed spatio-temporal sequence. The management of such work thus requires many people to be on-site and collocated to physically combine the material resources necessary to create, for example, a new retail development.

While the project manager was regularly required to be physically on site for much of the working day, this did not override the ongoing need to simultaneously engage in electronic communication. Indeed, as outlined above, the communication intensity of the work was one of its key features. The need to be constantly available to deal with electronic communication, and respond to calls an email promptly was visible in the following selected quotes, 'as soon as I stop actioning information .. people stop working', 'being a project manager involves having to be available', 'I'm normally the one talking on the phone as I'm walking to the [departure] gate'. Thus, the project manager had to 
manage the balance between the need to be physically mobile, being in certain locations when necessary, with constant electronic availability, to deal with ongoing issues where he was not copresent.

Finally, the above information gives insight into some of the ways in which the project manager's work impacted on his non-work life and social relations. Firstly, he regularly required to be absent from home, often travelling at unsociable hours (I've got to get up at stupid o'clock to get to the airport') although this was counterbalanced by the ability to work at home regularly. Further, his lack of time in the office meant that informal social relations with colleagues also suffered ('there never enough time just to have a social interaction .. the chit-chat over the coffee machine .. those things get compromised').

\subsection{Long haul plane-based travel: Corporate Finance Director}

The traveller used to illustrate travel at this, the largest spatial scale, is a senior manager (finance director) within a multi-site, multinational aerospace company with sites in the UK, mainland Europe, Singapore and the USA. He had an office base at the company's HQ in the UK, but was a very regular traveller, having a corporate role with responsibility for financial decisions within one division of the company which was dispersed across multiple sites. His travel patterns spanned both the short and long-haul spatial scales. His typical travel patterns were described as follows:' l'd be travelling to France for a couple of days a week every 2-3 weeks essentially, and to the USA probably once every two months, for 3 or 4 days.' Thus, he typically travelled on plane-based journeys every couple of weeks, with these journeys always involving an overnight stay, and when the trips were long haul flights, such as to the USA, they typically involved being away from home for a number of days. 
His travel was almost exclusively to the various sites of his employer, and his journeys were concerned with the corporate coordination of financial management at each company site. While his visits were typically structured around various on-site meetings, his business trips had a more general purpose, of providing an advisory, corporate presence. In explaining the purpose of his meeting he said: 'structured around meetings .. just being there to deal with things as they arise .. just having a presence there ..'

Indicative of the fact that a key part of his organizational role was to coordinate activities across sites was that despite the extensive amount of travel undertaken, or partly because of it, his role was communication intensive, involving the extensive use of electronic communications. This was summed up as follows: 'there's a significant amount of emails always flying around, so a [smartphone brand] is a fairly important tool'.

Further, the electronic communication activity represents one way in which his work intruded on non-work time. In talking about mobile phone use the interviewee said, "I keep the phone on 24 hours a day .. to see if there's any messages that require urgent attention'. This is partly argued to be necessary due to the international nature of the business, where time zone differences between offices mean emails often arrived in the evening or during the night, 'it's partly because we have a US business .. they're at work in our evenings..'. Such activity was recognised as sometimes being a source of domestic conflict, 'I've had comments on that from the wife ..' The other main way in which this interviewees travel patterns impacted on his non-work life was through the regular absences from home they had, which when trips were to the USA could involve being away for 4-5 days, with this often involving travelling on weekends. 


\section{Discussion}

'Inside each country, the networking architecture reproduces itself into regional and local centres, so that the whole system becomes interconnected at the global level', (Castells 1996, p. 380).

The article began by using Castell's concept of flows to help explain why a growing proportion of contemporary workers require to be spatially mobile to carry out their work. It is important to recognize that the flow of goods, information and people that sustains economic activity in a network-based society does not only occur on an international, global scale. In developing his analysis of the 'space of flows,' Castells devotes considerable space to discussing the different type of economic network that are evolving within a network-based economy, including those at a local level which are necessary to sustain global/informational cities such as New York, Tokyo, London, Singapore, regional networks which sustain regional innovation hubs, as well as the global networks which inter-connect these concentrated centres of economic activity. Thus, in talking about innovation in the high technology manufacturing centre, Castells quotes Amin and Robins (1991) who talk about how the new industrial system involves, 'a new articulation of global and local dynamics', (Castells 1996, p. 392). As the quotation which begins this section highlights, such flows happen at local as well as regional levels. Thus Castell's vision of a network-based economy is of flows occurring within networks at different spatial scales, all of which are important and necessary to sustain a globally interconnected economic system. The purpose of this article has been to take account of scale in considering the full diversity of work-related mobility patterns that contemporary workers engage in. 
The paper utilized four vignettes to illustrate Hislop's (2016) framework on spatial scales. This was useful, not only to create an awareness to and sensitivity regarding the local, regional as well as international scales that business travel occurs over, but to also highlight the different types of work that involve regular spatial mobility, how mobility at different spatial scales has differential impacts on the character and dynamics of people's work patterns, and, finally, the heterogeneous impact travel at different scales can have on people's non-work lives. Each of these issues is now examined in turn.

While three of the four vignettes above examined managerial and professional workers of different types, the inclusion of the mobile engineer undertaking localized land-based journeys is important. This usefully highlights how work-related mobility is not the exclusive domain of managerial and professional workers. Thus while the majority of academic studies on work-related mobility focus on managerial and professional workers, often undertaking international travel, and staying away from home overnight in doing so (Beaverstock et al 2010, Jeong et al 2013, Gustafson 2006), it is useful to remember that this represents only one type of work-related mobility. The case of the mobile engineers also provides some other useful insights into both the rationales for work-related mobility, and character of such work. In terms of rationales for engaging in work-related travel, the mobile engineer's case highlights how mobility may involve (and require) the mobility of goods between different locations, as well as requiring the presence of workers in particular spatio-temporal contexts to work with such material objects (see also Laurier \& Philo 2003). In the case of the mobile engineers their work required that they travel between different client sites to service and repair equipment. Such work required them to be physically present at particular locations at specific times, and involved them utilizing equipment and components they have brought with them. This usefully illustrates the materiality of work, and highlights how the spatial mobility of people is often necessary to allow the bringing together, assembly and or co-ordination of diverse (physical) objects. 
The third vignette, of the construction site project manager also illustrates this. Thus the successful construction of buildings on static building sites involves the carefully co-ordinated mobility of a diverse range of objects and people, as well as requiring the physical presence of a diverse range of workers to manage and undertake the construction process.

The vignettes from each spatial scale also illustrate the differential impact that travel at each scale has on working time, and the temporal rhythms of work. In terms of work hours in general, broadly, the larger the spatial scale that people travel across, the greater the impact on working hours. Thus the mobile engineer was the traveller who worked fixed predictable hours, and whose work and travel patterns had the least impact on non-work time. In contrast, the case of the corporate finance director examined, who regularly undertook journeys on the largest spatial scale, working hours were in general longest. While this may be significantly influenced by the type of role undertaken by this traveller, the nature of his travel patterns also significantly impacted on his working hours. Despite technological and logistical innovations in the travel industry, for example via faster trains, and via reductions in airport check-in times, via online check in etc., undertaking work-related travel is still relatively time consuming. Despite factors such as traffic congestion etc., the larger the spatial scale that people are travelling across, the longer travel time is likely to be. Further, while technological innovations now make it possible for people to devote much travel time to working (Hislop \& Axtell 2015), business travel often has to be done outside of 'normal office hours' in order for people to arrive on time for the face-to-face meetings they are travelling for. Thus overall work time (travel time plus non-travel work hours) is broadly linked to the amount of time devoted to work-related travel, with overall work time increasing as travel time increases. Overall therefore, travel time is one crucial factor (among many) affecting people's working time. 
The other differential impact that travel on different spatial scales has is on the temporal rhythms of work. In broad terms, the larger the spatial scale of people's journeys, the greater the likelihood that people undertaking such journeys will regularly require them to be absent from the home on a regular basis. Thus, as with the mobile engineer, when travel is on a localised scale, the need to be absent from home overnight due to work is relatively rare. This is because, for such workers, however much work time is devoted to travel, the spatial scale on which such journeys occur mean that people are typically able to get home at the end of the working day. However, with journeys undertaken on the three other spatial scales, the likelihood of work-related travel requiring regular home absences outside of work time is greater. Thus, long-distance land-based travel regularly requires people to leave home very early, or get home very late, short haul plane-based travel often requires travellers to stay away from home for at least one night for each journey they undertake, and long-haul plane-based travel typically involves people staying away home for a number of days at a time. For workers travelling on journeys at these scales, the temporal rhythm of work involved regular absences from home outside of normal work hours, with such absences varying dependent upon the type of travel being undertaken.

A final issue to touch on briefly was the information and communication networks that travellers at all spatial scales were embedded in, which significantly affected both the character of their work time, and the way in which work impacted on their non-work time. The only exception here was the mobile engineer, who, while using a mobile phone for his work, was able to switch it off and not use it after work, due to the nature of his employment contract (see also Hislop \& Axtell 2011). For the workers whose journeys spanned the three other spatial scales it was apparent that they were embedded in communication networks within which they were regularly required to engage. To undertake this work, all made extensive use of mobile ICTs throughout their working time, whether they were travelling or not. Thus, despite the amount of travel they all undertook, they still needed 
to communicate extensively with remote others. This aspect of their work also had a significant impact on their non-work lives. While the spatial scale across which people travel was found to have a differential impact on people's non-work lives, for the three travellers who made extensive use of mobile ICTs in their work, the impact of this aspect of their work on their non-work lives was broadly similar. Fundamentally, all three of these travellers found that, due to the expectations they felt to be constantly contactable for work, as well as perceptions that they required to respond promptly to relevant messages, engaging in work-related communication activity regularly intruded on their nonwork time. This blurring of the work-life boundary, and the encroachment of work into non-work time due to the use of mobile ICTs for work is consistent with other studies of these technologies (Duxbury et al 2014, Matusik \& Mickel 2012, Mazmanian et al 2013).

In drawing the article to a close it is useful to reflect on the potential limitations of both the spatial scales framework, and the empirical data that is used to illustrate it. In relation to the spatial scales framework itself, it is important to acknowledge that it is not being argued that this represents the primary feature shaping the nature of business traveller's work, and non-work lives. The focus on it here is purely due to its relative neglect. In accounting for how business travel impacts on people's work and non-work lives it is equally important to take account of factors such as how long people's journeys last (see for example Jones 2010), or how regularly people require to travel for work. Ultimately, to fully understand how the character of business travel impacts on people's work and non-work lives it is necessary to take account of all these diverse features of people's work-related travel patterns. Further, it is also useful to acknowledge that journeys on the same spatial scale are not necessarily homogeneous in their characteristics, or how they impact on workers. For example, journeys on the same spatial scale may vary in terms of how many separate journey stages are involved, and how many different modes of transport require to be used (for example, a direct flight between two long haul destinations, versus a journey between long haul destinations that are not 
directly connected by plane and which require people to use a number of flights, and other modes of transport). Equally, in considering long-haul plane-based journeys, the experience of undertaking them may be significantly affected by the number of time zones people cross. For example, while flying between London and Cape Town, and London and Shanghai involves travelling similar distances on planes, Cape town is only one hour different from London, while Shanghai is 8 hours different from London. Such a significant different is likely to make a journey from London to Shanghai more tiring than the journey from London to Cape Town. Ultimately, journeys on similar spatial scales can have quite different characteristics. Finally, , it should be acknowledged that a limitation of this framework is that in focussing on spatial scale purely in terms of geographic distance, it doesn't take account of the more subjective, cultural and relational aspects of spatial scale, related to how people make sense of and experience it.

The second limitation to acknowledge relates to the UK-centric nature of the empirical data that was collected. It is important to acknowledge that the types of work-related travel undertaken by those who participated in this study are a reflection of the character of the UK economy (such as the type of economic activity undertaken, the extent to which economic activity is regionally, and internationally inter-connected), the nature of the UKs transport infrastructure (such as the characteristics of the UK's train and road system), as well as the specific physical and human geography of the UK (being an island, located close to mainland Northern Europe, which is relatively small in geographic terms, and with variable levels of population density in different regions). Thus, the patterns of business travel undertaken in other, quite different geographic areas, with different characteristics, may be different. Thus, to evaluate the generalizability of the spatial scales framework utilized here, it is necessary to conduct studies of business travel in other, quite different geographic areas. 


\section{Conclusion}

In combining Castells' (1996) work on spatial scale, with Hislop's (2016) framework on the different spatial scales of business travel to analyse the experiences of a heterogeneous range of workers who regularly travel for work, the paper fits with one of the aims of Applied Mobilities to publish theoretically informed, applied work on (work-related) mobilities. This paper is embedded in the literature on work-related travel, and contributes to this burgeoning body of work through highlighting the diverse spatial scales the work-related travel involves, as well as illustrating how the spatial scale of people's work-related journeys can have a significant impact on both the nature of their work and non-work lives. The paper questions the predominant focus of much relevant literature on international travel undertaken by managerial and professional workers, and adds to knowledge by providing insights into other, relatively neglected, types of work-related travel.

\section{References}

Axtell, C, Hislop, D (2008) The Lonely life of the Mobile Engineer? In Hislop, D (ed) Mobility and Technology in the Workplace. London: Routledge.

Aguilera, A (2008) Business Travel and Mobile Workers. Transportation Research Part A, 42: 11091116.

Beaverstock, J, Faulconbridge, J (2010) 'Official' and 'Unofficial' Measurements of International Business Travel to and From the United Kingdom: Trends, Patterns and Limitations. In Beaverstock, J, Derudder B, Faulconbridge J and Witlox F (eds) International Business Travel in the Global Economy. Farnham: Ashgate. 
Beaverstock J, Derudder, B Faulconbridge J and Witlox, F (2010) International Business Travel and the Global Economy: Setting the Context. In Beaverstock, J, Derudder B, Faulconbridge J and Witlox F (eds) International Business Travel in the Global Economy. Farnham: Ashgate.

Castells, M (1996) The Rise of Network Society. Oxford: Blackwell.

Cohen, R (2010) Rethinking 'mobile work': Boundaries of Space, Time and Social Relation in the Working Lives of Mobile Hairstylists'. Work, Employment and Society 24: 65-84.

Duxbury, L, Higgins, C, Smart, R, Stevenson, M (2014) Mobile Technology and Boundary Permeability. British Journal of Management, 25: 570-588.

Faulconbridge, J, Muzio, D (2008) Organizational Professionalism in Globalizing Law Firms. Work, Employment and Society, 22: 7-25.

Faulconbridge, J, Beaverstock, J, Derudder, B, Witlox, F (2009) Corporate Ecologies of Business Travel in Professional Service Firms: Working Towards a Research Agenda. European Urban and Regional Studies, 16: 295-308.

Felstead, A, Jewson, N, Walters S (2005) Changing Places of Work. Basingstoke, UK: Palgrave MacMillan.

Ferguson, H (2009) Driven to Care: The Car, Automobility and Social Work. Mobilities 4(2): 275-293.

Gustafson, P (2006) Work-related Travel, Gender, and Family Obligations. Work, Employment and Society 20(3): 513-530.

Hislop, D (2016) Agents of the Network Society: Spatial Mobility among Managerial and Professional Workers. In Wilkinson, A, Hislop, D, Coupland, C (eds), Perspectives on Contemporary Professional Work: Challenges and Experiences, Edward Elgar: Cheltenham, UK. 
Hislop, D, Axtell, C (2009) To Infinity and Beyond? Workspace and the Multi-Location Worker. New Technology, Work and Employment, 24: 60-75.

Hislop D, Axtell, C (2011) Mobile Phones During Work and Non-Work Time: A Case Study of Mobile, Non-Managerial Workers. Information and Organization, 21: 41-56.

Hislop, D, Axtell, C (2015) The Work-Related Affordances of Business Travel: A Disaggregated Analysis of Journey Stage and Mode of Transport, Work, Employment and Society.

Holm, J, Kendall, G (2008) Working on the Move: Subverting the Logic of non-space. In Hislop, D (ed) Mobility and Technology in the Workplace. London: Routledge.

Jeong Y-J, Zvonkovic A, Sano Y, Acock A (2013) The occurrence and Frequency of Overnight Business Travel in the USA. Work, Employment and Society, 27: 138-152.

Jones, A (2010) Understanding Mobility in Professional Business Services, In Beaverstock, J, Derudder B, Faulconbridge J, Witlox F (eds) International Business Travel in the Global Economy. Farnham: Ashgate.

Knox, H, O’Doherty, D, Vurdubakis, T, Westrup, C (2008) Enacting Airports: Space, Movement and Modes of Ordering. Organization, 15: 869-888.

Lassen, C (2009) A Life in Corridors: Social Perspectives on Aeromobility and work in Knowledge Organizations, In Cwerner, S, Kesselring, S, Urry, J (eds) Aeromobilities. Abingdon: Routledge.

Laurier, E, Philo, C (2003) The Region in the Boot: Mobilising Lone Subjects and Multiple Objects. Environment and Planning D: Society and Space, 21: 85-106.

Lilischkis, S. (2003) More yo-yos, pendulums and nomads: trends of mobile and multi-location work in the information society. Bonn, Germany: Empirica (STAR Issue Report No. 36.) 
Matusik, S, Mickel, A (2012) Embracing or Embattled by Converged Mobile Devices? Users'

Experiences with a Contemporary Connectivity Technology. Human Relations, 64: 1001-1018.

Mazmanian, M, Orlikowski, W, Yates, J (2013) The Autonomy Paradox: The Implications of Mobile Email Devices for Knowledge Professionals. Organization Science, 24: 1337- 1357.

Pica, D, Sørensen, C (2008). Context Matters: Un-ubiquitous Use of Mobile Technologies by the Police. In Hislop, D (ed) Mobility and Technology in the Workplace. London: Routledge.

Sørensen, C, Pica, D. (2005) Tales from the police: Rhythms of interaction with mobile technologies. Information \& Organization, 15: 125-149.

Wibberley, G (2013) Getting the Bodies of the Workers to the Bodies of the Clients: the Role of the Rota in Domiciliary Care. In: Wolkowitz C, Cohen R, Sanders T and Hardy K (eds) Body/Sex/Work. Basingstoke: Palgrave Macmillan.

Wickham, J, Vecchi, A (2010) Hierarchies in the Air: Varieties of Business Air Travel. In, Beaverstock, J, Derudder B, Faulconbridge J and Witlox F (eds) International Business Travel in the Global Economy. Farnham: Ashgate. 
Figure 1: Journey Type and Geographic Distance

Long-distance Land-based Journeys Long-Haul Plane-based Journeys Localized land-based Journeys Short-Haul Plane-based Journeys

Geographic Distance 